\title{
Estrogen and Preeclampsia: Potential of Estrogens as Therapeutic Agents in Preeclampsia
}

\author{
Chang Shu' \\ Shumei Han ${ }^{2}$ \\ Peng $\mathrm{Xu}^{3}$ \\ Ying Wang' \\ Tingting Cheng' \\ Cong $\mathrm{Hu} \mathbb{1}^{4}$ \\ 'Department of Obstetrics and \\ Gynecology, The First Hospital of Jilin \\ University, Jilin University, Changchun, \\ Jilin, I3006I, People's Republic of China; \\ ${ }^{2}$ Department of Medical Administration, \\ The First Hospital of Jilin University, Jilin \\ University, Changchun, Jilin, I3002I, \\ People's Republic of China; ${ }^{3}$ Department \\ of Sports Medicine, The First Hospital of \\ Jilin University, Jilin University, \\ Changchun, Jilin, I3002I, People's \\ Republic of China; ${ }^{4}$ Reproductive Center, \\ The First Hospital of Jilin University, Jilin \\ University, Changchun, Jilin, I3002I, \\ People's Republic of China
}

\begin{abstract}
There is a significant decline in the estrogen levels in preeclampsia, and exogenous administration of estradiol normalizes blood pressure and other associated symptoms of preeclampsia. The decrease in estrogen levels may be due to changes in enzyme activities of hydroxysteroid (17- $\beta$ ) dehydrogenase 1 , aromatase, and COMT. There is also a decrease in the novel, estrogenic G-protein-coupled receptor 30 (GPR30) in the placental trophoblast cells in preeclampsia. The activation of GPR30 protects the placenta from hypoxiareoxygenation injury, decreases apoptosis and increases proliferation through eNOS and PI3K-Akt signaling pathways. Estrogens may also increase $\mathrm{Ca}^{2+}$-activated $\mathrm{K}^{+}$channel function, decrease the release of inflammatory cytokines, and oxidative stress to improve placental perfusion. Both preclinical and clinical studies show the decrease in the 2-methoxyestradiol levels in preeclampsia, which may be due to a decrease in estradiol itself along with a decrease in the enzymatic actions of the COMT enzyme. 2-Methoxyestradiol activates HIF $1 \alpha$ and vascular endothelial growth factor receptors (VEGFR-2) to maintain placental perfusion by increasing angiogenesis. The present review discusses the preclinical and clinical studies describing the role of estrogen in preeclampsia along with possible mechanisms.
\end{abstract}

Keywords: estradiol, oxidative stress, hypertension, inflammation, perfusion

\section{Introduction}

Preeclampsia is one of the most common causes of maternal and fetal mortality worldwide. ${ }^{1}$ Preeclampsia is characterized by placental hypoxia, reduction in uteroplacental perfusion and progressive rise in blood pressure. ${ }^{2}$ As per the American College of Obstetrics and Gynecology, preeclampsia is defined as the state of pregnancy with systolic blood pressure $\geq 140 \mathrm{mmHg}$ systolic or diastolic blood pressure $\geq 90 \mathrm{mmHg}$ after 20 weeks of gestation along with significant proteinuria $(>300 \mathrm{mg} / 24$ hours or protein/creatinine ratio $>0.20)$. In preeclampsia, organ failure very common, and due to persistent hypertension, there may be the malfunction of kidneys, liver, and lungs. ${ }^{3}$ The development of hypoxia, initiation of inflammation and an increase in oxidative stress may contribute to inducing endothelial dysfunction, which may be important in reducing perfusion of the placenta. $^{4}$

Estrogen is an important female sex hormone, and it produces several important functions in the female genital system. Amongst its different functions, the role of estradiol in maintaining placental perfusion has been identified. Indeed, a very early study in 1932 showed the vascular effects of estrogens and it was shown that crude follicular estrogen results in vasodilatation in the uterine endometrial tissue. ${ }^{5}$
Correspondence: Cong Hu

Reproductive Center, The First Hospital of Jilin University, Jilin University, No. 7I Xinmin Street, Changchun, Jilin, I3006I, People's Republic of China

Email conghu@jlu.edu.cn 
Subsequent studies supported this finding and showed that estrogens are the potent vasodilators and increase the blood flow to several organs, including the uterus. ${ }^{6,7}$ Owing to its vasodilatory actions, a rise in the estrogen levels during pregnancy may contribute to maintaining the uteroplacental vascular functions. Indeed, it has been found to induce and maintain uterine vasodilation during pregnancy. ${ }^{8,9}$ The mechanisms involved in estrogenmediated maintenance of uteroplacental vascular function are identified. However, it has been proposed that estrogen may produce vasodilation indirectly through prostacyclin, ${ }^{10}$ nitric oxide, ${ }^{11}$ or endothelium-derived hyperpolarizing factor (EDHR). ${ }^{12}$ Estrogen produces its actions through $E R \alpha$ and ER $\beta$ receptors, which usually initiate transcriptional changes. However, the acute vasodilatory actions of estrogen have been attributed to the non-genomic actions of ER $\alpha$ and ER $\beta .^{13}$ Interestingly, estrogen has also been found to produce rapid, nongenomic vasodilatory actions via transmembrane G-protein-coupled receptor 30 (GPR30). ${ }^{14}$

Since there is a considerable role of estrogen in maintaining the uteroplacental vascular function, it has been postulated that a decrease in estrogen levels may contribute in compromising the placental perfusion during pregnancy. Indeed, several clinical studies have documented a significant decrease in the levels of estradiol during preeclampsia. ${ }^{15}$ Accordingly, the exogenous administration of estrogen has been shown to produce beneficial effects in animal models as well as in preeclampsia patients. ${ }^{16,17}$ The precise mechanisms responsible for the decrease in estrogen levels are not clear. It may be possible that the changes in estrogen levels may be due to variations in its metabolism during pregnancy. ${ }^{18,19}$ The present review discusses the preclinical and clinical studies describing the role of estrogen in preeclampsia along with possible mechanisms.

\section{Preclinical Studies Showing the Role of Estrogen in Preeclampsia}

There have been studies showing the key role of estrogen in the pathobiology of preeclampsia-like features in animals.

\section{Exogenous Estrogen Reduce the Symptoms in Experimental Models}

In an endotoxin perfusion-induced experimental model of preeclampsia in 14-day-pregnant rats, injection of $17 \beta-$ estradiol $(1 \mathrm{mg} / \mathrm{kg} / \mathrm{d})$ was shown to significantly reduce the blood pressure and albuminuria. Moreover, it also attenuated the expression of inflammation-associated adhesion molecule $\mathrm{CD}(49 \mathrm{~d})$ and $\mathrm{TNF}-\alpha$ levels in a significant manner. It suggests that $17 \beta$-estradiol has the potential to improve the symptoms of experimental preeclampsia, which may be due to a decrease in the levels of inflammatory mediators. ${ }^{20}$ Exogenous administration of estradiol has also been shown to produce beneficial effects in L-NAMEinduced preeclampsia model in rats by preventing the inflammation and preserving the endothelial functions. In pregnant rats receiving a daily i.p. injection of L-NAME and $100 \mu \mathrm{g} / \mathrm{kg}$ estradiol, there was a significant decline in the blood pressure and 24-h urine protein in comparison to only L-NAME-receiving pregnant rats. Treatment with L-NAME increased the blood pressure, urinary protein, rate of stillbirths and suppressed fetal weight as compared to normal control animals. Administration of estradiol attenuated L-NAME-induced deleterious effects in a pregnant state. Besides, estradiol increased the levels of nitric oxide and decreased the levels of inflammatory cytokines, including IL-1 $\beta$ (Figure 1), IL-6, IFN- $\gamma$, monocyte chemoattractant protein-1, intracellular adhesion molecule 1 and lymphocyte function-associated antigen-1. ${ }^{21}$

2-Methoxyestradiol is a metabolite of estradiol and is derived by the action of the enzyme catecholO-methyltransferase (COMT). In COMT-deficient pregnant mice, preeclampsia-like features have been identified in these mice along with a significant decline in 2-methoxyestradiol levels. It is possible that the deficiency of 2-methoxyestradiol indirectly signifies the deficiency of estradiol in preeclampsia; however, this relationship is not very completely proven. Furthermore, exogenous administration of 2-methoxyestradiol was shown to ameliorate all preeclampsialike features in pregnant mice. ${ }^{22}$ However, it should be very clear that, unlike humans, animals do not develop preeclampsia and there are important structural differences in the placental anatomy of animals and humans. Therefore, the animal models of preeclampsia do not truly represent the preeclampsia-like state in humans. Nevertheless, these animal models are very useful for the preliminary investigation of drugs with the potential to lower blood pressure during pregnancy.

\section{Mechanisms Involved in Producing Beneficial Effects of Estrogens in Preeclampsia $\mathrm{Ca}^{2+}$-Activated $\mathrm{K}^{+}$Channel Function}

The presence of large-conductance $\mathrm{K}_{\mathrm{Ca}}\left(\mathrm{Ca}^{2+}\right.$-activated $\mathrm{K}^{+}$ channel function) on the endothelium is involved in 


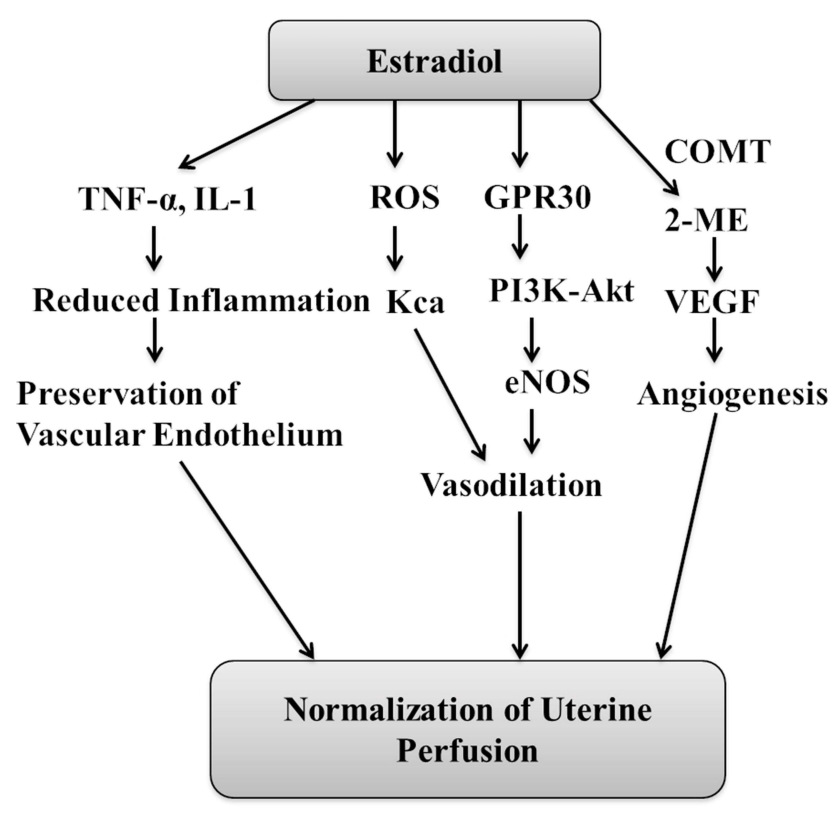

Figure I Representative diagram showing the possible mechanisms that may contribute in estradiol-mediating maintenance of uterine perfusion during pregnancy. The decrease in estradiol levels may blunt these protective mechanisms and may lead to the development of preeclampsia.

Abbreviations: 2-ME, 2-methoxyestradiol; COMT, catechol-O-methyltransferase; VEGF, vascular endothelial growth factor; ROS, reactive oxygen species; GPR30, G-protein-coupled receptor 30 .

regulating vascular tone by inducing smooth muscle relaxation. $^{23}$ There have been studies showing that the upregulation of $\mathrm{Ca}^{2+}$-activated $\mathrm{K}^{+}$channel plays a key role in the normal adaptation of uterine arteries during pregnancy and chronic hypoxia-induced downregulation of these channels may contribute to the development of preeclampsia. ${ }^{24}$ Through in vitro studies involving uterine arterial smooth muscle cells in pregnant animals, it has been shown that estrogens may increase the large-conductance $\mathrm{K}_{\mathrm{Ca}}\left(\mathrm{Ca}^{2+}\right.$ activated $\mathrm{K}^{+}$channel function) in the uterus to decrease preeclampsia and associated complication. Indeed, it has been shown that hypoxia triggers the production of free radicals, which may inhibit large-conductance $\mathrm{K}_{\mathrm{Ca}}$. Hypoxiainduced increase in oxidative stress was shown to abolish the estrogen-induced increase in large-conductance $\mathrm{K}_{\mathrm{Ca}}$. These negative effects of free radicals were abolished in the presence of antioxidant, $\mathrm{N}$-acetyl cysteine. It suggests the hypoxia-mediated increase in free radicals may negatively regulate the functions of estrogen on the large-conductance $\mathrm{K}_{\mathrm{Ca}}$ to induce the development of preeclampsia (Figure 1). ${ }^{25}$

\section{Vascular Endothelial Growth Factor Receptors (VEGFR-2)}

Vascular endothelial growth factor (VEGF) is an endogenous angiogenesis promoting factor and the decrease in
VEGF has been related to the development of preeclampsia. ${ }^{26}$ It is also identified that an excess of placental expressed soluble fms-like tyrosine kinase-1 scavenges VEGF to induce generalized endothelial dysfunction. $^{27}$ Accordingly, various interventions to restore the angiogenic balance in preeclamptic pregnancies have been found to improve maternal and neonatal outcomes. $^{28}$ Using the first trimester of human placental villous explants, it has been shown that 2-methoxyestradiol may act by modulating vascular endothelial growth factor receptors (VEGFR-2). It was shown that exposure of placental villous explants to hypoxia produced preeclampsia-like features, including an increase in soluble fms-like tyrosine kinase-1 (antiangiogenic factor). There was also a decrease in the protein and transcript levels of VEGFR-2. However, overnight treatment with 2-methoxyestradiol rescued altered expression levels of VEGFR-2, sFlt-1 and HIF1 $\alpha$. It possibly suggests that 2-methoxyestradiol may be beneficial in attenuating preeclampsia-like features by modulating VEGFR-2 (Figure 1). ${ }^{29}$

\section{G-Protein-Coupled Receptor 30, eNOS and Akt}

G-protein-coupled receptor 30 (GPR30) is a novel estrogen receptor and these receptors are reported to play a key role in several estrogenic effects. It has been reported that there is a decrease in the expression of GPR30 in the placental extravillous trophoblast cells in the preeclamptic placenta. Moreover, treatment with $17 \beta$-estradiol has been shown to increase the GPR30 expression on the placental HTR8/SVneo cells. ${ }^{30}$ It has been well reported that the maintenance of appropriate trophoblast cell invasion is very important for a normal pregnancy. On the other hand, the defective trophoblast invasion results in shallow placental implantation and inadequate remodeling of the uterine spiral arteries. It may result in hypoperfusion of the placenta and the development of preeclampsia. ${ }^{31}$ Using immortalized human trophoblast cell-line HTR8/SVneo, the key role of estradiol in inducing trophoblast invasion has been described. Indeed, it has been shown that the selective GPR30 agonist G1 and 17- $\beta$-estradiol improve trophoblast cell invasion through PI3K-Akt signaling pathway. However, pretreatment with a selective GPR30 inhibitor G15 was shown to abolish these effects, implying that estradiol may be involved in trophoblast invasion through activation of GPR30. ${ }^{2}$ Another study has shown that selective GPR30 agonist G1 and 17- $\beta$-estradiol protect the cultured extravillous trophoblasts (placental tissue removed at the end of pregnancy and cells grown in the 
culture media) from the hypoxia-reoxygenation injury. Indeed, these cells were protected from apoptotic cell death and showed higher proliferation in the presence of G1 and 17- $\beta$-estradiol. However, the addition of selective GPR30 inhibitor G15 was shown to abolish the protective effects of G1 and 17- $\beta$-estradiol, suggesting the key role of GPR30 in regulating cell survival and cell proliferation in the hypoxia-subjected placenta during preeclampsia. ${ }^{32}$

Human umbilical vein endothelial cells (HUVECs) are derived from the endothelium of veins of the umbilical cord and have been extensively employed as a laboratory model system to study the function and pathology of endothelial cells including angiogenesis. ${ }^{33}$ Using human umbilical vein endothelial cells (HUVECs), it has been shown that 17- $\beta$ estradiol promotes angiogenesis through activation of GPR30. It was reported that hypoxia led to a significant decline in the total pipe length of the tube-like structure in endothelial cells, suggesting the inhibitory effects of hypoxia on angiogenesis. However, treatment with 17- $\beta$-estradiol significantly attenuated the hypoxia-induced decrease in angiogenesis. Treatment with estradiol also increased the expression levels of GPR30, endothelial nitric oxide synthase (eNOS) and p-Akt levels in the endothelial cells. However, pretreatment with Wortmannin, an inhibitor of PI3K/Akt, significantly attenuated the expression of eNOS and prevented endothelial cell tube formation in estradioltreated cells. Accordingly, it was proposed that 17- $\beta$ estradiol activates GPR30 to stimulate eNOS and Akt signaling in the endothelial cells to promote placental angiogenesis, ${ }^{34}$ which may contribute to overcoming placental insufficiency during preeclampsia.

\section{Clinical Studies}

\section{Decrease in the Estrogen Levels and Its Biosynthetic Enzymes \\ Decrease in the Estrogen Levels}

There have been studies showing a decrease in the plasma levels of estrogen in preeclampsia patients. ${ }^{35} \mathrm{~A}$ clinical study identified a significant alteration in the homeostasis of gonadal hormones in preeclampsia patients. It was identified that there was a significant decrease in the levels of estrogen and progesterone, along with a rise in the testosterone content. Furthermore, it was identified that there was a significant decline in the nitric oxide levels in the blood, which possibly signified the presence of endothelial dysfunction. Accordingly, it may be possible that reduction in the levels of estrogen and progesterone may induce endothelial dysfunction to decrease the levels of vasodilatory molecule, nitric oxide, which may contribute to the development of preeclampsia. ${ }^{36}$ In preeclamptic pregnancies, the underexpression of estradiol along with upregulation of mRNA and protein levels of estradiol receptors has been reported. The decrease in estradiol levels may be responsible for increasing the expression of estradiol receptors. Accordingly, it is suggested that dysregulation of estradiol and estrogen receptors may contribute to the pathogenesis of preeclampsia. ${ }^{37}$ More studies have shown a decrease in the plasma levels of estradiol-17 $\beta$ and estrone in preeclampsia of varying severity, suggesting that the aberrant synthesis and metabolism of estrogens contribute to the pathogenesis of preeclampsia. ${ }^{18,19}$ Due to abnormal metabolism, it has been identified that there is a relative increase in the high plasma levels of 16-keto-estradiol with concomitant low levels of estradiol-17 $\beta$ and estriol in women with severe preeclampsia. The high levels of this 16-keto-estradiol may be the result of aberrant metabolic changes and may contribute to the development of preeclampsia. ${ }^{18}$ However, there is a need for more studies to identify the precise changes in the estrogen metabolic pathways that may contribute to reducing estradiol levels in preeclampsia. A clinical study involving 86 preeclamptic and 97 gestation-matched normotensive pregnancies has shown a significant decrease in the serum levels of estrogen and progesterone, which may contribute to impairing placental function in preeclampsia. ${ }^{38} \mathrm{~A}$ very recent clinical study has identified that there is a significant decrease in estradiol levels during preeclampsia along with a decrease in ER $\alpha$ protein, with no significant change in the ER $\beta$ levels in the nucleus and cytoplasm of syncytiotrophoblasts and stromal cells. ${ }^{39}$

\section{Alteration in 17 $\beta$-Hydroxysteroid Dehydrogenase and Aromatase Enzymes}

Hydroxysteroid (17- $\beta$ ) dehydrogenase 1 (HSD17B1) is a steroidogenic enzyme and it catalyzes the conversion of estrone (less active estrogen) to $17 \beta$-estradiol (more active estrogen). It has been shown that there is a decrease in the plasma levels of HSD17B1 in preeclampsia women. Moreover, it has also been shown that HSD17B1 is an independent risk factor for predicting the onset of preeclampsia in pregnant women in the second trimester. Therefore, a decrease in plasma levels of HSD17B1 may contribute to the development of preeclampsia. ${ }^{40}$ Another study revealed the presence of significantly lower estradiol and estrone levels in the plasma of women with 
preeclampsia. The decreased circulating levels of estrogens were attributed to significantly lower expression of placental aromatase. Moreover, it was reported that dysregulation of steroidogenesis appeared much earlier than the appearance of symptoms of preeclampsia, which suggests that the abnormalities in steroidogenesis may be employed as important markers to diagnose preeclampsia before the appearance of clinical symptoms. ${ }^{41}$

Along with it, there is also a significant change in the enzymatic activities of 17 $\beta$-HSD3 (an enzyme involved in testosterone synthesis) and aromatase (an enzyme involved in converting androgens to estrogens) in preeclamptic placentas. Indeed, it has been shown that there is a significant increase in 17ß-HSD3 and a decrease in aromatase in the preeclamptic placentas, which may contribute in reducing the estrogen levels in the plasma during preeclampsia. It was found that testosterone directly repressed the expression of aromatase, while it promoted the miR-22 expression in the preeclamptic placenta. In turn, miR-22 directly inhibited estrogen receptor $\alpha$ expression and indirectly decreased aromatase expression and estradiol production by interfering with estrogen receptor $\alpha$ signaling. It suggests that an increase in testosterone represses estrogen signaling by upregulating miR-22 in the placenta, and this imbalanced steroid hormone production may be critical in the development of preeclampsia. ${ }^{42}$ There is another study showing a significant decrease in placental aromatase activity in preeclampsia patients. ${ }^{41}$

\section{Decrease in COMT Activity Leading to Decrease in 2-Methoxyestradiol Levels}

2-Methoxyestradiol is a metabolite of estradiol, which is produced by the metabolic actions of COMT. However, apart from just a metabolite of estradiol, it renders important physiological actions in the reproductive system of females. ${ }^{43}$ It has been documented that the plasma levels of 2-methoxyestradiol are significantly reduced in preeclampsia patients ${ }^{44}$ and this reduction may be possibly due to a decrease in COMT activity ${ }^{45}$ and a decrease in estradiol levels. ${ }^{46}$ In preeclampsia patients with 11 to 14 -week pregnancy, a significant decline in the plasma levels of 2-methoxyestradiol has been reported. ${ }^{47}$ There have been more studies showing a decrease in the 2-methoxyestradiol levels in mild to severe preeclampsia in comparison to normotensive full-term pregnancies. ${ }^{48}$ In a study involving 28 severe preeclampsia patients, low levels of 2-methoxyestradiol were reported, which were negatively correlated with systolic pressure, diastolic pressure and mean arterial pressure. Thus, it provides clinical evidence that 2-methoxyestradiol deficiency is strongly related to the development of hypertension in early-onset severe preeclampsia. The patients fulfilling at least one of the criteria of high systolic blood pressure (160 $\mathrm{mm} \mathrm{Hg}$ ), high diastolic blood pressure $(110 \mathrm{~mm} \mathrm{Hg})$ or proteinuria $(2 \mathrm{~g} / 24 \mathrm{~h})$ were classified in the category of severe preeclampsia. ${ }^{49}$ In preeclampsia women during the third trimester of gestation, a significant decrease in the concentration of 2-methoxyestradiol (1818.41 \pm $189.25 \mathrm{pg} / \mathrm{mL}$ ) was documented in the plasma in comparison to normal control pregnancy $(2906.43 \pm 200.69 \mathrm{pg} / \mathrm{mL})$. The risk of preeclampsia was decreased as the levels of 2-methoxyestradiol increased in these patients. The 2-methoxyestradiol values were negatively correlated with the systolic peak arterial pressure and proteinuria in preeclampsia. Women with lower 2-methoxyestradiol levels had a more serious clinical condition and required more aggressive therapy. ${ }^{50}$ On the contrary, a rise in the serum levels of 2-methoxyestradiol has been reported in late-onset preeclampsia. A rise in the levels of 2-methoxyestradiol in patients with late-onset preeclampsia may possibly be due to activation of compensatory mechanisms to maintain the serum estrogen levels to normal. ${ }^{51}$

\section{Exogenous Administration of Estrogen Exerts Protective Actions}

In a clinical study, short-term intramuscular treatment with estradiol has been shown to attenuate blood pressure during preeclampsia state in pregnancy. Moreover, estradiol therapy (17 $\beta$-estradiol $10 \mathrm{mg}$, IM for three days at $9 \mathrm{AM}$ ) to preeclamptic women (36-37 gestation weeks) led to a significant decrease in the levels of oxidative parameters including superoxide anion, hydrogen peroxide, peroxynitrite and lipid peroxide in erythrocytes. Moreover, the decrease in blood pressure was positively correlated with the reduction in oxidative stress in erythrocytes during estradiol therapy. It suggests that short-term intramuscular administration of estradiol exhibits antioxidative effects in erythrocytes and reduces blood pressure in preeclampsia. ${ }^{17}$ The choice of erythrocytes was made on the basis that it has been shown that the markers of oxidative stress are higher in erythrocytes and are directly associated with the rise in mean arterial pressure in preeclampsia. Moreover, oxidative stress in erythrocytes has also been directly linked to the development of endothelial cell dysfunction in preeclampsia. ${ }^{52}$ There has been another clinical study 
documenting that short-term estradiol therapy may contribute to normalizing the blood pressure in preeclampsia patients. Intramuscular injection of 17-beta-estradiol $(10 \mathrm{mg})$ was shown to decrease mean arterial blood pressure in preeclampsia patients. Moreover, it significantly attenuated the markers of oxidative stress including the plasma superoxide anion, hydrogen peroxide, and peroxynitrite. A positive correlation was reported between a decrease in the mean arterial blood pressure and a decrease in the markers of oxidative stress. Accordingly, it may be proposed that the short-term estradiol therapy may normalize mean arterial pressure in preeclampsia patients by decreasing the plasma oxidative stress. ${ }^{16}$ There have been several studies showing that the beneficial effects of estradiol may be due to its free radical scavenging actions ${ }^{53,54}$ The precise mechanisms responsible for the antioxidant actions of estradiol are not precisely clear. It has been suggested that the antioxidant effects of estradiol are independent of the activation of estrogen receptors. On the other hand, the antioxidant actions of estradiol may be due to the presence of a free phenolic hydroxyl group on the A-ring. ${ }^{55}$ The decrease in mean arterial pressure in response to estradiol therapy has also been attributed to its free radical scavenging actions. It has been proposed that due to the free radical scavenging actions of estradiol, not enough free radicals remain to react with nitric oxide and form peroxynitrite. As a consequence, the availability of nitric oxide is increased that may induce vasodilation and participate in decreasing the mean arterial blood pressure in preeclampsia. ${ }^{16}$

\section{Summarized Discussion and Conclusion}

Clinical studies have shown that there is a significant decline in the estrogen levels in preeclampsia. ${ }^{18,35}$ It is important to mention that preeclampsia has two subtypes, early-onset and late-onset, and these two subtypes have different etiology. ${ }^{56}$ However, there are insufficient studies to describe the relative role of estradiol in these two subtypes of preeclampsia. There has been a study describing that there is no significant difference in the serum levels of estradiol between early-onset and late-onset preeclampsia. ${ }^{38}$ On the other hand, it has been suggested that 2-methoxyestradiol deficiency is associated with early-onset preeclampsia, ${ }^{49}$ while a rise in the serum levels of 2-methoxyestradiol has been reported in late-onset preeclampsia. ${ }^{51}$ Nevertheless, there is a need for more clinical studies to explore the role and mechanisms of estradiol in two different subtypes of preeclampsia.

The important contribution of the decreased levels of estradiol in the development of preeclampsia is supported by the finding showing that the exogenous administration of estradiol normalizes the blood pressure and other associated symptoms of preeclampsia in animal models ${ }^{20,21}$ and preeclampsia patients. ${ }^{16,17}$ The decrease in estrogen levels may be due to multifold changes in enzyme activities including a decrease in HSD17B1 (responsible for converting estrone to estradiol), aromatase (synthesis of estradiol), COMT (required for the synthesis of 2-methoxyestradiol). ${ }^{40,41,45}$ Furthermore, a significant decrease in novel estrogen receptors, GPR30 has also been identified in the placental trophoblast cells in the preeclamptic placenta. $^{30}$ It has been identified that the activation of GPR30 protects the placenta from hypoxiareoxygenation injury, decreases apoptosis and increases proliferation through eNOS and PI3K-Akt signaling pathway. ${ }^{34}$ Moreover, it is also possible that estrogens increase the function of $\mathrm{Ca}^{2+}$-activated $\mathrm{K}^{+}$channel function, ${ }^{25}$ decrease the release of inflammatory cytokines, oxidative stress to improve placental perfusion. ${ }^{20,21}$ There is also a key role of 2-methoxyestradiol, a metabolite of estradiol, in preeclampsia as both preclinical and clinical studies have shown its reduced levels. The decrease in the levels of 2-methoxyestradiol may be due to a decrease in estradiol itself along with a decrease in the enzymatic actions of the COMT enzyme. One of the most important mechanisms of 2-methoxyestradiol involves the activation of HIF $1 \alpha$ and vascular endothelial growth factor receptors (VEGFR-2) during placental hypoxia that helps to maintain placental perfusion by increasing angiogenesis. ${ }^{29}$ Based on these, it may be concluded that the lack of endogenous production of estrogen may contribute significantly to the pathogenesis of preeclampsia and thus, exogenous estrogenic administration may be therapeutically exploited in the management of preeclampsia.

\section{Conclusion}

There is a decrease in the endogenous production of estrogen in preeclampsia and thus, exogenous estrogenic administration may be therapeutically exploited in the management of preeclampsia. Estrogen-mediated beneficial effects may involve the activation of GPR30, eNOS and PI3K-Akt signaling pathway. It may also increase the function of $\mathrm{Ca}^{2+}$-activated $\mathrm{K}^{+}$channel function, decrease the release of inflammatory cytokines and oxidative stress 
to improve placental perfusion. 2-methoxyestradiol may activate HIF $1 \alpha$ and vascular endothelial growth factor receptors to maintain placental perfusion.

\section{Funding}

This study was supported by fundings from NSFC (Natural Science Foundation of China) 81501279, Finance Department of Jilin Province, China (Grant JLSCZD2019053), Natural Science Funds in Science and Technology Department of Jilin Province, China (Grant 20160101058JC) (http://www.jlkjxm.com/) and Open Project of Key Laboratory of Organ Regeneration and Transplantation, Ministry of Education (Grant Number 15).

\section{Disclosure}

The authors report no conflicts of interest in this work.

\section{References}

1. Mol BWJ, Roberts CT, Thangaratinam S, Magee LA, de Groot CJM, Hofmeyr GJ. Pre-eclampsia. Lancet Lond Engl. 2016;387 (10022):999-1011. doi:10.1016/S0140-6736(15)00070-7

2. Tong C, Feng X, Chen J, et al. G protein-coupled receptor 30 regulates trophoblast invasion and its deficiency is associated with preeclampsia. $\quad J$ Hypertens. 2016;34(4):710-718. doi:10.1097/ HJH.0000000000000844

3. Bokslag A, van Weissenbruch M, Mol BW, de Groot CJM. Preeclampsia; short and long-term consequences for mother and neonate. Early Hum Dev. 2016;102:47-50. doi:10.1016/j. earlhumdev.2016.09.007

4. Hutcheon JA, Lisonkova S, Joseph KS. Epidemiology of pre-eclampsia and the other hypertensive disorders of pregnancy. Best Pract Res Clin Obstet Gynaecol. 2011;25(4):391-403. doi:10.1016/j.bpobgyn.2011.01.006

5. Markee JE. An analysis of the rhythmic vascular changes in the uterus of the rabbit. Am J Physiol-Leg Content. 1932;100 (2):374-382. doi:10.1152/ajplegacy.1932.100.2.374

6. Dickson W, Bosc M, Locatelli A. Effect of estrogen and progesterone on uterine blood flow of castrate sows. Am J Physiol-Leg Content. 1969;217(5):1431-1434. doi:10.1152/ajplegacy.1969.217.5.1431

7. Reynolds LP, Kirsch JD, Kraft KC, Knutson DL, McClaflin WJ, Redmer DA. Time-course of the uterine response to estradiol-17 $\beta$ in ovariectomized ewes: uterine growth and microvascular development1. Biol Reprod. 1998;59(3):606-612. doi:10.1095/ biolreprod59.3.606

8. Mandalà $\mathrm{M}$. Influence of estrogens on uterine vascular adaptation in normal and preeclamptic pregnancies. Int J Mol Sci. 2020;21:7. doi:10.3390/ijms21072592

9. Bai J, Qi QR, Li Y, et al. Estrogen receptors and estrogen-induced uterine vasodilation in pregnancy. Int J Mol Sci. 2020;21(12):4349. doi:10.3390/ijms 21124349

10. Korita D, Itoh H, Sagawa N, et al. 17beta-estradiol up-regulates prostacyclin production in cultured human uterine myometrial cells via augmentation of both cyclooxygenase-1 and prostacyclin synthase expression. J Soc Gynecol Investig. 2004;11(7):457-464. doi:10.1016/j.jsgi.2004.04.002

11. Veille JC, Li P, Eisenach JC, Massmann AG, Figueroa JP. Effects of estrogen on nitric oxide biosynthesis and vasorelaxant activity in sheep uterine and renal arteries in vitro. Am J Obstet Gynecol. 1996;174(3):1043-1049. doi:10.1016/s0002-9378(96)70348-4
12. Burger NZ, Kuzina OY, Osol G, Gokina NI. Estrogen replacement enhances EDHF-mediated vasodilation of mesenteric and uterine resistance arteries: role of endothelial cell Ca2+. Am J Physiol Endocrinol Metab. 2009;296(3):E503-512. doi:10.1152/ajpendo.90517.2008

13. Mayra PR, Rosalina VL, López G, Iruretagoyena J, Magness R. [Regulation of uterine blood flow. II. Functions of estrogen and estrogen receptor $\alpha / \beta$ in genomic and non-genomic actions of the uterine endothelium]. Rev Chil Obstet Ginecol. 2014;79(3):218-228. [Spanish]. doi:10.4067/S0717-75262014000300011

14. Fredette NC, Meyer MR, Prossnitz ER. Role of GPER in estrogen-dependent nitric oxide formation and vasodilation. J Steroid Biochem Mol Biol. 2018;176:65-72. doi:10.1016/j. jsbmb.2017.05.006

15. Berkane N, Liere P, Oudinet JP, et al. From pregnancy to preeclampsia: a key role for estrogens. Endocr Rev. 2017;38(2):123-144. doi:10.1210/er.2016-1065

16. Babic GM, Markovic SD, Varjacic M, et al. Estradiol decreases blood pressure in association with redox regulation in preeclampsia. Clin Exp Hypertens. 2018;40(3):281-286. doi:10.1080/10641963.2017.1368538

17. Djordjević NZ, Babić GM, Marković SD, Ognjanović BI, Stajn AS, Saicić ZS. The antioxidative effect of estradiol therapy on erythrocytes in women with preeclampsia. Reprod Toxicol. 2010;29 (2):231-236. doi:10.1016/j.reprotox.2009.11.004

18. Jobe SO, Tyler CT, Magness RR. Aberrant synthesis, metabolism, and plasma accumulation of circulating estrogens and estrogen metabolites in preeclampsia implications for vascular dysfunction. Hypertension. 2013;61(2):480-487. doi:10.1161/HYPERTENSIONAHA.111.201624

19. Cantonwine DE, McElrath TF, Trabert B, et al. Estrogen metabolism pathways in preeclampsia and normal pregnancy. Steroids. 2019;144:8-14. doi:10.1016/j.steroids.2019.01.005

20. Wang X, Xiong Q, Wang C, et al. [Study of estradiol on treatment of preeclampsia in rat model]. Zhonghua Fu Chan Ke Za Zhi. 2005;40 (11):739-742. [Chinese].

21. Lin Z-H, Jin J, Shan X-Y. The effects of estradiol on inflammatory and endothelial dysfunction in rats with preeclampsia. Int $J$ Mol Med. 2020;45(3):825-835. doi:10.3892/ijmm.2020.4465

22. Kanasaki K, Palmsten K, Sugimoto $H$, et al. Deficiency in catechol-O-methyltransferase and 2-methoxyoestradiol is associated with pre-eclampsia. Nature. 2008;453(7198):1117-1121. doi:10.1038/ nature 06951

23. Coleman HA, Tare M, Parkington HC. Endothelial potassium channels, endothelium-dependent hyperpolarization and the regulation of vascular tone in health and disease. Clin Exp Pharmacol Physiol. 2004;31(9):641-649. doi:10.1111/j.1440-1681.2004.04053.x

24. Hu XQ, Xiao D, Zhu R, et al. Chronic hypoxia suppresses pregnancy-induced upregulation of large-conductance $\mathrm{Ca} 2+$-activated $\mathrm{K}+$ channel activity in uterine arteries. Hypertension. 2012;60 (1):214-222. doi:10.1161/HYPERTENSIONAHA.112.196097

25. Zhu R, Huang X, Hu XQ, Xiao D, Zhang L. Gestational hypoxia increases reactive oxygen species and inhibits steroid hormone-mediated upregulation of $\mathrm{Ca}(2+)$-activated $\mathrm{K}(+)$ channel function in uterine arteries. Hypertension. 2014;64(2):415-422. doi:10.1161/HYPERTENSIONAHA.114.03555

26. Kwiatkowska E, Stefańska K, Zieliński M, et al. Podocytes-the most vulnerable renal cells in preeclampsia. Int J Mol Sci. 2020;21 (14):5051. doi:10.3390/ijms21145051

27. Matin M, Mörgelin M, Stetefeld J, et al. Affinity-enhanced multimeric VEGF (vascular endothelial growth factor) and PlGF (placental growth factor) variants for specific adsorption of sFlt-1 to restore angiogenic balance in preeclampsia. Hypertension. 2020;76 (4):1176-1184. doi:10.1161/HYPERTENSIONAHA.120.14974

28. Wang X, Yang L, Chen Y, Zhang L, Fei H. Ghrelin promotes angiogenesis by activating the Jagged1/Notch2/VEGF pathway in preeclampsia. J Obstet Gynaecol Res. 2021;47(2):486-494. doi:10.1111/jog.14555 
29. Lee DK, Nevo O. 2-Methoxyestradiol regulates VEGFR-2 and sFlt-1 expression in human placenta. Placenta. 2015;36(2):125-130. doi:10.1016/j.placenta.2014.11.013

30. Feng X, Zhou L, Mao X, et al. Association of a reduction of G-protein coupled receptor 30 expression and the pathogenesis of preeclampsia. Mol Med Rep. 2017;16(5):5997-6003. doi:10.3892/ mmr.2017.7341

31. Goldman-Wohl D, Yagel S. Regulation of trophoblast invasion: from normal implantation to pre-eclampsia. Mol Cell Endocrinol. 2002;187(1-2):233-238. doi:10.1016/s0303-7207(01)00687-6

32. Li J, Chen Z, Zhou X, et al. Imbalance between proliferation and apoptosis-related impaired GPR30 expression is involved in preeclampsia. Cell Tissue Res. 2016;366(2):499-508. doi:10.1007/ s00441-016-2466-y

33. Cao Y, Gong Y, Liu L, et al. The use of human umbilical vein endothelial cells (HUVECs) as an in vitro model to assess the toxicity of nanoparticles to endothelium: a review. J Appl Toxicol. 2017;37 (12):1359-1369. doi:10.1002/jat.3470

34. Zhou L, Chen H, Mao X, Qi H, Baker PN, Zhang H. G-proteincoupled receptor 30 mediates the effects of estrogen on endothelial cell tube formation in vitro. Int $J$ Mol Med. 2017;39(6):1461-1467. doi:10.3892/ijmm.2017.2957

35. Pecks U, Rath W, Kleine-Eggebrecht N, et al. Maternal serum lipid, estradiol, and progesterone levels in pregnancy, and the impact of placental and hepatic pathologies. Geburtshilfe Frauenheilkd. 2016;76(7):799-808. doi:10.1055/s-0042-107078

36. Zhorzholadze ED, Sanikidze TV, Dzhikiia IV. The role of hormonal homeostasis in pathogenesis of endothelial dysfunction during preeclampsia. Georgian Med News. 2006;130:104-107.

37. Yin G, Zhu X, Guo C, et al. Differential expression of estradiol and estrogen receptor $\alpha$ in severe preeclamptic pregnancies compared with normal pregnancies. Mol Med Rep. 2013;7(3):981-985. doi: $10.3892 / \mathrm{mmr} .2013 .1262$

38. Wan $\mathrm{J}, \mathrm{Hu} \mathrm{Z}$, Zeng $\mathrm{K}$, et al. The reduction in circulating levels of estrogen and progesterone in women with preeclampsia. Pregnancy Hypertens. 2018;11:18-25. doi:10.1016/j.preghy.2017.12.003

39. Lan KC, Lai YJ, Cheng HH, et al. Levels of sex steroid hormones and their receptors in women with preeclampsia. Reprod Biol Endocrinol. 2020;18(1):12. doi:10.1186/s12958-020-0569-5

40. Ohkuchi A, Ishibashi O, Hirashima $\mathrm{C}$, et al. Plasma level of hydroxysteroid (17- $\beta$ ) dehydrogenase 1 in the second trimester is an independent risk factor for predicting preeclampsia after adjusting for the effects of mean blood pressure, bilateral notching and plasma level of soluble fms-like tyrosine kinase 1/placental growth factor ratio. Hypertens Res. 2012;35(12):1152-1158. doi:10.1038/hr.2012.109

41. Berkane N, Liere P, Lefevre G, et al. Abnormal steroidogenesis and aromatase activity in preeclampsia. Placenta. 2018;69:40-49. doi:10.1016/j.placenta.2018.07.004

42. Shao X, Liu Y, Liu M, et al. Testosterone represses estrogen signaling by upregulating miR-22: a mechanism for imbalanced steroid hormone production in preeclampsia. Hypertension. 2017;69 (4):721-730. doi:10.1161/HYPERTENSIONAHA.116.08468

43. Pinto MP, Medina RA, Owen GI. 2-methoxyestradiol and disorders of female reproductive tissues. Horm Cancer. 2014;5(5):274-283. doi:10.1007/s12672-014-0181-2
44. Perez-Sepulveda A, España-Perrot PP, Norwitz ER, Illanes SE. Metabolic pathways involved in 2-methoxyestradiol synthesis and their role in preeclampsia. Reprod Sci. 2013;20(9):1020-1029. doi: $10.1177 / 1933719113477483$

45. Taravati A, Tohidi F, Moniri M, Kamali K. CatecholO-methyltransferase gene polymorphism (Val158Met) and development of pre-eclampsia. Arch Med Res. 2017;48(2):180-186. doi:10.1016/j.arcmed.2017.03.006

46. Wantania J, Attamimi A, Siswishanto RA. Comparison of 2-methoxyestradiol value in women with severe preeclampsia versus normotensive pregnancy. J Clin Diagn Res. 2017;11(3):QC35-QC38. doi:10.7860/JCDR/2017/21516.9603

47. Pérez-Sepúlveda A, Torres MJ, Valenzuela FJ, et al. Low 2-methoxyestradiol levels at the first trimester of pregnancy are associated with the development of pre-eclampsia. Prenat Diagn. 2012;32(11):1053-1058. doi:10.1002/pd.3954

48. Shen Z, Wu Y, Chen X, et al. Decreased maternal serum 2-methoxyestradiol levels are associated with the development of preeclampsia. Cell Physiol Biochem. 2014;34(6):2189-2199. doi:10.1159/000369662

49. Zhang Y, Wang T, Shen Y, Wang X, Baker PN, Zhao A. 2-Methoxyestradiol deficiency is strongly related to hypertension in early onset severe pre-eclampsia. Pregnancy Hypertens. 2014;4 (3):215-219. doi:10.1016/j.preghy.2014.04.004

50. Pertegal M, Fenoy FJ, Bonacasa B, et al. 2-methoxyestradiol plasma levels are associated with clinical severity indices and biomarkers of preeclampsia. Reprod Sci. 2015;22(2):198-206. doi:10.1177/ 1933719114537716

51. Seol HJ, Cho GJ, Oh MJ, Kim HJ. 2-methoxyoestradiol levels and placental catechol-O-methyltransferase expression in patients with late-onset preeclampsia. Arch Gynecol Obstet. 2013;287 (5):881-886. doi:10.1007/s00404-012-2663-1

52. Dordević NZ, Babić GM, Marković SD, et al. Oxidative stress and changes in antioxidative defense system in erythrocytes of preeclampsia in women. Reprod Toxicol. 2008;25(2):213-218. doi:10.1016/j.reprotox.2007.11.001

53. Mendelsohn ME. Protective effects of estrogen on the cardiovascular system. Am J Cardiol. 2002;89(12A):12E-17E. doi:10.1016/s00029149(02)02405-0

54. Wing LYC, Chen YC, Shih YY, Cheng JC, Lin YJ, Jiang MJ. Effects of oral estrogen on aortic ROS-generating and -scavenging enzymes and atherosclerosis in apoE-deficient mice. Exp Biol Med. 2009;234 (9):1037-1046. doi:10.3181/0811-RM-332

55. Prokai L, Prokai-Tatrai K, Perjési P, Simpkins JW. Mechanistic insights into the direct antioxidant effects of estrogens. Drug Dev Res. 2005;66(2):118-125. doi:10.1002/ddr.20050

56. Aneman I, Pienaar D, Suvakov S, Simic TP, Garovic VD, McClements L. Mechanisms of key innate immune cells in earlyand late-onset preeclampsia. Front Immunol. 2020;11:1864. doi:10.3389/fimmu.2020.01864

\section{Publish your work in this journal}

Drug Design, Development and Therapy is an international, peerreviewed open-access journal that spans the spectrum of drug design and development through to clinical applications. Clinical outcomes, patient safety, and programs for the development and effective, safe, and sustained use of medicines are a feature of the journal, which has also been accepted for indexing on PubMed Central. The manuscript management system is completely online and includes a very quick and fair peer-review system, which is all easy to use. Visit http://www. dovepress.com/testimonials.php to read real quotes from published authors. 